\title{
Factors Affecting Public Transport in Petaling Jaya, Malaysia: An Extension of the Theory of Planned Behaviour
}

\author{
A. Madha, H. Dhafir, A. Dawood \\ UKM \\ Bangi, Selangor, Malaysia \\ aprodigy9@yahoo.com; husseinoo_85@yahoo.com; alialshock@yahoo.com
}

\begin{abstract}
In order to understand travellers' willingness to use the train in Petaling Jaya, this study adds four predictors situational factors, trust, novelty seeking and external influence - to the existing model of theory of planned behaviour (TPB). The study collected research data from employees in Petaling Jaya, Malaysia, resulting in an effective data of 400 participants. Results indicate that attitude, perceived behavioural control, and subjective norm are found to have positive effects on the behavioural intention of taking the train. Furthermore, novelty seeking, trust, and external influence also have positive influences on attitude, the three antecedents of the intention, and the subjective norm in taking the train respectively. While situational factors were found to have a negative influence on attitude towards behavioural intention to take the train.
\end{abstract}

Keywords: Public transport, Private car, Theory of planned behaviour, Structural equation modelling; Petaling jaya.

\section{Introduction}

Transport infrastructure is an indispensable component of successful development, for it induces the creation of new attractions and the growth of existing ones [01]. With different trip purposes and trip lengths, people make different choices of travel mode [02]. The train has the possibility to attract travelers who previously chose to travel by car and can also provide new opportunities for long distance commuting which is too long for daily travel by personal vehicles. However, it is not clear what drives the travelers to take the train. To examine the process, this study applies the theory of planned behavior (TPB) as the research framework to predict the behavioral intention of taking the train. TPB, a widely used model to predict and explain human behavior, has been applied to a variety of social behaviors with strong predictive utility (e.g., [03]; [04]; [05]; [06]). Furthermore, additional constructs are suggested to enhance the predictive power of TPB [07], and thus this study employs situational factors, novelty seeking, trust and external influence to the original TPB theory.

\subsection{Theory of planned behaviour}

Theory of Planned Behaviour, TPB: is a model that has been applied extensively to explain and predict human behaviour across various disciplines [08], such as psychology, health, technology applications, education, the environment, business, security and transportation. TPB is an extension of the theory of reasoned action TRA that was founded by Martin Fishbein and Icek Ajzen in 1975 [09].

The TPB can be regarded as a generalization of the theory of reasoned action [10]. According to the TRA, the most important determinant of a person's behavior is the intention to perform a behavior. Intention is defined as a combination of attitude and subjective norm. Attitude toward a behavior is the degree to which the performance of the behavior is positively or negatively valued. Subjective norm is defined as perceived social pressure to engage or not to engage in a behavior. According to Fishbein and Ajzen [09], the stronger the behavioural intention, the more likely the individual will perform a behaviour. Ajzen [11] expanded TRA to TPB by adding another predictor that measures perceived behavioural control, PBC. Perceived behaviour control refers to the individual's perception of their capability to perform a particular behaviour. The predictor of perceived behaviour control is linked directly to intention and behaviour.

\subsection{Hypotheses}

Constructs in the TPB model are used to examine the relationship between trust, situation factors, attitudes, subjective norms, perceived behavioural control, novelty seeking and external influences with intention use public transportation to work. Applied to this study, the TPB suggests that a person is more likely to use public transport 
instead of other travel modes if he/she has a positive attitude toward using public transport, and who is influenced by the opinion of family members, friends and colleagues to use public transport, as well as people who would take into consideration the external influences promoting public transport and have the necessary resources, the ability, or the opportunity to use public transport. Therefore, the previous discussion can be summarized in the following hypotheses:

Hypothesis 1: Attitude is positively related to people's intention to take the train.

Hypothesis 2: Subjective norm is positively related to people's intention to take the train.

Hypothesis 3: Perceived behavioural control is positively related to people's intention to take the train.

Situation predictors' factors are defined as physical factors that can facilitate or inhibit a behaviour [12]. In this study, situation predictors are seen as factors that could prevent or promote the use of public transport. . People can show positive attitudes towards using public transportation to reduce congestion on the road and help reduce environmental pollution caused by cars, but this does not mean they are willing to use public transport in real situations. There are several factors that prevent them from using public transport such as the provision of free parking at work, poor conditions of public transport facilities, the limited transport routes covered by public transport network, prolonged journey using public transport and the remote location of transport stations. Therefore, the following hypothesis is proposed as follows:

Hypothesis 4: Situation Factors are negatively related to people's attitude to take the train.

Consumer trust is defined as the expectations held by the consumer in which the service provider is dependable and can be relied upon to deliver its promises [13]. For trust to exist, consumers must believe that the trustee has both the ability and the motivation to reliably deliver the expected quality goods or services [14]. Trust is usually formed as specific beliefs, so it has influence not only on behavioural intention but also on the antecedents of intention [15].

Hsiao and Yang [16] have extended the TPB in their study of the use of high-speed trains among students in Taiwan. In the study, trust has been linked to the intentional behaviour through attitude, subjective norms and perceived behavioural control. In order to better understand the relationships between the belief structures and the antecedents of intention, these hypotheses were proposed:

Hypothesis 5: Trust is positively related to the attitude to take the train.

Hypothesis 6: Trust is positively related to the subjective norm to take the train.

Hypothesis 7: Trust is positively related to perceived behavioural control to take the train.

Novelty seeking is often regarded as a curiosity drive or an exploratory drive which would influence consumers' attitudes toward technological products or travel destination choice [17]. Hsiao and Yang assumed that in the decisionmaking of travel mode choice, tourists with higher propensity of novelty seeking would hold more positive attitude towards new kind of transportation. Therefore, the following hypothesis is proposed:

Hypothesis 8: Novelty seeking is positively related to people's attitude toward the train.

While subjective norms have a more interpersonal influence expressed by friends, colleagues and family members, external influence on the other hand indicates mass media reports, expert opinions, and other non-personal information considered by individuals when performing a behaviour. Bhattacherjee [18] found that external influence is an important predictor of subjective norms. Therefore, the following hypothesis is proposed:

Hypothesis 9: External Influence is positively related to people's subjective norm to take the train.

\section{Methodology}

\subsection{Participants}

About a 100 questionnaires were completed through a series of one on one interviews. This method was the most effective in terms of informational accuracy but was not carried out extensively due to the lack of time and manpower. In residential areas about 200 copies of the questionnaire were placed in mailboxes of residents and were collected later on from the management office, though not all of them were included in the study as some of the collected 
questionnaires were incomplete and missing important data. Also, after discussions with the administration of some of the local companies, the distribution of some 200 copies was submitting to the management and the results were collected after a few days. The data was collected in about three months. Between 400 and 500 copies were distributed, though about 400 copied were used in the final study.

\subsection{Measures}

Eight constructs were measured in this study regarding the TPB data. Initial scale items were taken from previously validated measures and revised to relate specifically to the present study. All items were measured using a 5 point Likert scale, ranging from 1 = "Strongly Disagree" to 5 = "Strongly Agree", while the scale of 3 indicates a "not sure" or "neutral" response. Behavioural intention was measured using four-item scales taken from [19], [20] and [18]. Attitude, Subjective norm and PBC were adapted from [20]. Situational factors and Trust both were measured using scales adapted from the work of [04]. Novelty seeking was adapted from the works of [21], [22], and [16]. The external influence was a variation of [18]'s scale, adapted to fit the wider notion of this construct.

\section{Results}

In the process of developing the SEM model in this study, two methods of approach (measurement model and structural model) are used that has been proposed and recommended by [23], [24] and [25] to assess the construct validity, the appropriateness of the model and to test the hypotheses.

\subsection{Measurement model}

As a preliminary step, the original TPB model was replicated using our obtained data. After running the model, the results show an overall satisfactory goodness of fit indices. , with Relative Chi-squared $(\chi 2 / \mathrm{df})$ of 1.744 , and other fit indices: GFI $=0.93$, AGFI $=0.91$, TLI $=0.96, \mathrm{CFI}=0.97, \mathrm{RMR}=0.049$, RMSEA $=0.041$. The next step in producing the model is developing the SEM measurement model and to validate it. Confirmatory factor analysis (CFA) method is used to remove or drop items in the constructs that have a loading factor that is less than 0.5 or insignificant ([24]; [16]; [26]; [27]. Moreover, the analysis is used to assess the reliability of the items and the reliability of the constructs. As shown in Table 1, the overall goodness-of-fit indices of CFA indicate a satisfactory fit of the measurement model, with Relative Chi-squared $(\chi 2 / \mathrm{df})$ of 1.558 , and other fit indices: GFI $=0.89, \mathrm{AGFI}=0.86$, TLI $=$ $0.95, \mathrm{CFI}=0.96, \mathrm{RMR}=0.053, \mathrm{RMSEA}=0.040$.

To validate our measurement model, three types of validity were carried out: content validity, convergent validity, and discriminant validity. Content validity was initiated by ensuring consistency between the measurement items and the previous literature. Convergent validity was poised by examining composite reliability (CR) and average variance extracted (AVE) from the measures [24]. As shown in Table 1, the composite reliabilities (CR) in this study ranging from 0.805 to 0.911 , all exceed the recommend threshold of 0.50 [24]. Furthermore, the average variances extracted (AVE) range from .529 to .719 , which are also above the acceptable value of 0.50 . In addition, Table 1 shows the loadings of the measures in our research model. Most paths in the measurement model have a loading factor above 0.5 . Table 2 shows the intercorrelations for all variables. The results show a significant correlation among behavioural intention and other constructs.

Fornell and Larcker [28] stated that cause-squared AVE for each construct should exceed the correlations value between the constructs with other constructs. The AVE for each construct will be squared right at source and will be compared with the correlation between the constructs. The analysis of the cause-squared AVE of the constructs of intention, attitude, situational factors, subjective norms, perceived behaviour control, novelty seeking, trust, and external influence for the measurement model is higher than the correlation between the constructs as shown in table 2 . This shows a higher source-squared AVE value compared to the correlations between the constructs, this means that the discriminant validity has met the conditions. Table 1 shows a summary of the discriminant validity of the measurement model.

\subsection{Structural model}

By modifying the measurement models, a complete structural model was developed to test or examine the cause of relationship structure as proposed in the theoretical model in this study. Results of the analysis resulted in the construct of a complete structure of the model as illustrated in Figure 3. AMOS 20 software is used to evaluate the suitability of the model and the path of suggested hypotheses. The results showed that most fit indices are below acceptable levels $(\chi 2 / \mathrm{df}=1.567, \mathrm{GFI}=0.88, \mathrm{AGFI}=0.86, \mathrm{TLI}=0.95, \mathrm{CFI}=0.96, \mathrm{RMSEA}=0.040$. According to [14] the GFI can be increased to 0.90 by dropping items with small factor loadings, however, the researcher chose not 
to drop more items in this study. According to some researchers, it is normal that in some studies using SEM models rarely demonstrate the excellent suitability for all indices ([29]; [30]).

Table 1: Standardized loadings and reliability.

\begin{tabular}{|c|c|c|c|c|c|c|c|}
\hline $\begin{array}{l}\text { Constructs } \\
\text { and items }\end{array}$ & loading factor & $\begin{array}{l}\text { Reliability } \\
\text { composite }\end{array}$ & AVE & $\begin{array}{l}\text { Constructs } \\
\text { and items }\end{array}$ & $\begin{array}{l}\text { loading } \\
\text { factor }\end{array}$ & $\begin{array}{l}\text { Reliability } \\
\text { composite }\end{array}$ & AVE \\
\hline Intention & & 0.849 & 0.592 & $\begin{array}{l}\text { Perceived } \\
\text { behaviour } \\
\text { control }\end{array}$ & & 0.868 & 0.529 \\
\hline IN1 & 0.686 & & & PB1 & 0.796 & & \\
\hline IN2 & 0.909 & & & PB2 & 0.848 & & \\
\hline IN3 & 0.843 & & & PB3 & 0.857 & & \\
\hline \multirow[t]{2}{*}{ IN4 } & 0.660 & & & PB4 & 0.644 & & \\
\hline & & & & PB5 & 0.654 & & \\
\hline Attitude & & 0.890 & 0.582 & PB6 & 0.521 & & \\
\hline ATT1 & 0.752 & & & & & & \\
\hline ATT2 & 0.919 & & & $\begin{array}{l}\text { Novelty } \\
\text { seeking }\end{array}$ & & 0.911 & 0.719 \\
\hline ATT3 & 0.899 & & & NS1 & 0.898 & & \\
\hline ATT4 & 0.668 & & & NS2 & 0.884 & & \\
\hline ATT5 & 0.732 & & & NS3 & 0.837 & & \\
\hline ATT6 & 0.631 & & & NS4 & 0.711 & & \\
\hline \multirow[t]{2}{*}{ ATT7 } & Dropped* & & & & & & \\
\hline & & & & Trust & & 0.926 & 0.643 \\
\hline $\begin{array}{l}\text { Situational } \\
\text { factors }\end{array}$ & & 0.805 & 0.580 & TR1 & Dropped* & & \\
\hline SF1 & Dropped* & & & TR2 & 0.702 & & \\
\hline SF2 & 0.814 & & & TR3 & Dropped* & & \\
\hline SF3 & Dropped* & & & TR4 & 0.866 & & \\
\hline SF4 & 0.762 & & & TR5 & 0.795 & & \\
\hline \multirow[t]{2}{*}{ SF5 } & 0.706 & & & TR6 & 0.764 & & \\
\hline & & & & TR7 & 0.898 & & \\
\hline $\begin{array}{l}\text { Subjective } \\
\text { norms }\end{array}$ & & 0.810 & 0.590 & TR8 & 0.791 & & \\
\hline SN1 & 0.715 & & & TR9 & 0.821 & & \\
\hline SN2 & 0.886 & & & & & & \\
\hline \multirow[t]{4}{*}{ SN3 } & 0.690 & & & $\begin{array}{l}\text { External } \\
\text { influence }\end{array}$ & & 0.756 & 0.511 \\
\hline & & & & EI1 & 0.515 & & \\
\hline & & & & EI2 & 0.781 & & \\
\hline & & & & EI3 & 0.830 & & \\
\hline
\end{tabular}

Table 2: Correlations between constructs.

\begin{tabular}{|l|l|l|l|l|l|l|l|l|}
\hline & IN & AT & SF & SN & PBC & NS & TR & EI \\
\hline IN & $\mathbf{0 . 7 7 0}$ & & & & & & & \\
\hline AT & 0.372 & $\mathbf{0 . 7 6 3}$ & & & & & & \\
\hline SF & 0.009 & -0.214 & $\mathbf{0 . 7 6 2}$ & & & & & \\
\hline SN & 0.256 & 0.121 & -0.030 & $\mathbf{0 . 7 6 8}$ & & & & \\
\hline PBC & 0.257 & 0.166 & -0.133 & 0.151 & $\mathbf{0 . 7 2 8}$ & & & \\
\hline NS & 0.155 & 0.223 & -0.057 & 0.175 & 0.140 & $\mathbf{0 . 8 4 8}$ & & \\
\hline TR & 0.126 & 0.274 & -0.070 & 0.249 & 0.197 & 0.244 & $\mathbf{0 . 8 0 2}$ & \\
\hline EI & 0.175 & 0.065 & -0.003 & 0.206 & 0.014 & 0.071 & 0.024 & $\mathbf{0 . 7 1 5}$ \\
\hline
\end{tabular}


With a sufficient measurement model, structured equation modelling is used to examine the causal structure of the proposed model in this study. By examining the standardized path coefficients, we found that most of the paths are significant at 0.01 levels except for a few which are significant at 0.05 levels. As a result, all paths are significant and in the expected direction. Hypotheses 1-3 are supported as they have been in many studies by applying TPB to explain behavioural intentions. Attitude $(b=0.221, \mathrm{p}<0.001)$, subjective norm $(\mathrm{b}=0.183, \mathrm{p}<0.001)$, and perceived behavioural control $(b=0.206, p<0.01)$ all positively influencing behavioural intention of using public transport in Petaling Jaya. Situational factors have a significant negative influence on the attitude of the respondents towards the behavioural intention to use the train among workers in Petaling Jaya. This finding supports hypothesis 4 . Situation factors $(b=-0.23, p<0.05)$ is seen as a negative influences that can prevent users from using the train. The results show that trust has indirect significant influences on students' intention to take the train via attitude $(b=0.273, p$ $<0.001)$, subjective norm $(b=0.221, p<0.001)$, and perceived behavioural control $(b=0.149, p<0.001)$. Hypothesis 8 is supported $(b=0.217 ; p<0.05)$, indicating that novelty seeking is the antecedent of attitude. Hypothesis 9 is supported as well $(b=0.246 ; p<0.01)$ indicating that external influence is an important predictor of subjective norms.

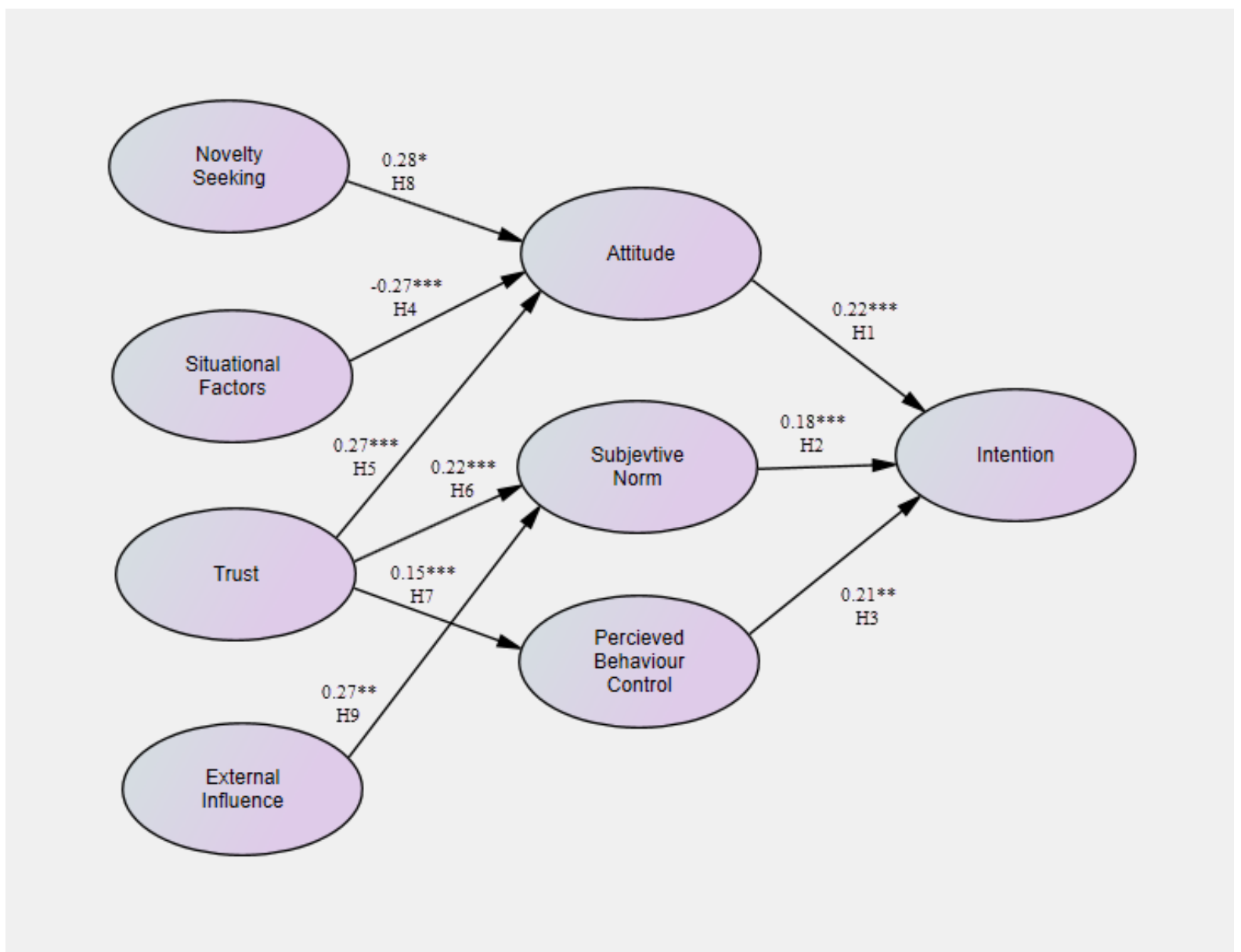

Fig. 1: Result of the research model. Notes: *p $<.05 ; *$ p $<.01 ; * *$ p $<.001$.

\section{Discussion}

The results indicate that a favourable attitude toward using the train has the most decisive influence on the behavioural intention among the three factors. Therefore, the Majlis Bandaraya Petaling Jaya can attract riders by enhancing a positive disposition about itself. Next, the effect of perceived behavioural control on intention is also strong only less than attitude. Therefore, acceptable fare and convenient access are suggested to improve commuter's ability to take the train. Last, subjective norm has the least effect on intention as many researches stated ([19]; [31]). The weak effect of subjective norm implies that in the domestic travel market, travellers can make their own decisions independently while arranging their leisure activities with less need for further consultation from families or friends.

Situation factors are seen as negative influences that can prevent users from using the train. There are three indicators in situational factors construct as shown in Table 1 that affect the use of train to work with significant value. One of the reasons preventing workers from using the train is caused by the long distance between the train station and 
work and home, where respondents said travelling to the nearest train station effects their travel preference. The second factor which prevents the use of train by employees is because employees think that using the train will increase their travel time to get to work. And finally, the last factor is a lack of a sophisticated train operation network, most respondents stated that their destinations not being covered by train routes is a major reason for choosing private transport over the train.

The results show that trust has an indirect significant influence on commuters' intention to take the train via attitude, subjective norm, and perceived behavioural control. It indicates that low intention to take the train may be credited to unfavourable attitude towards the train, which in turn is influenced by the trust towards the train. Trust is as critical in attitude-enhancing as novelty seeking is, because for traveling, reliability and safety are the most important traits sought by commuters. As Berry [32] stressed that "trust is the basis for loyalty", Majlis Bandaraya Petaling Jaya can enhance a favourable attitude toward the train by promoting its trustworthy brand image. By doing so, MBPJ should exhibit its maintenance and management ability clearly. Moreover, higher quality service and comfortable seats must be provided and maintained.

The results also show that novelty seeking influences the intention to take the train indirectly via attitude. Novelty seeking is the natural motivation to seek out new stimuli, new experiences, and novel products [16]. Low intention to take the train is influenced significantly by commuters' tendency of novelty seeking. Therefore, promotions about new stimuli and novel experiences of trips could enhance the favourableness of position and consideration towards the train, leading to a stronger willingness to take it. External influence is generated through advertisements in online and offline media, and promotional offers. External influence is important in individuals' formation of subjective norms toward train use.

There are some limitations of the current study that needs to be addressed. First, there are two aspects to novelty seeking, one regarding new train users that might find using the train as a novel exciting experience as many Malaysians haven't had the need to use the train before while regular train users who frequently use the train won't consider using the train as a stimulating exciting new experience, this might lead to some inconsistent results. Also, it is recommended that future studies could consider incorporating other important factors, such as comfort, security, accessibility, reliability, dependability, and time and budget constraints. By including some of the above important variables, a more fitted model might be obtained.

\section{References}

[1] R. Kaul, Dynamics of tourism: A triology, transporation and marketing. Nova Delhi: Sterling Publishers, 1985.

[2] N. Georggi and R. Pendyala, "Analysis of long-distance travel behavior of the elderly and low income. Transportation Research Circular," in Washington DC: Transportation Research Board, 1999, pp. 121-150.

[3] J. Reinecke, P. Schmidt and I. Ajzen, "Application of the theory of planned behavior to adolescents' condom use: A panel study," Journal of Applied Social Psychology, vol. 26, no. 9, pp.749-772, 2006.

[4] M. Nazri, "The Effectiveness of Public Transport System in Putrajaya: A Modelling Approach," Ph.D. dissertation, Dept. Engineering and Built Environment, Universiti Kebangsaan, Malaysia.

[5] L. Chan and B. Bishop, "A moral basis for recycling: Extending the theory of planned behaviour," Journal of Environmental Psychology, vol. 36, pp. 96-102, 2013.

[6] I.J. Donald, S.R. Cooper and S.M. Conchie, "An extended theory of planned behavior model of the psychological factors affecting commuters' transport mode use," Journal of Environmental Psychology, 2014.

[7] M. Conner and C. Abraham, "Conscientiousness and the theory of planned behavior: Toward a more complete model of the antecedents of intentions and behavior," Personality and Social Psychology Bulletin, vol. 27, no. 11, pp. 1547-1561, 2001.

[8] I. Ajzen, "The theory of planned behaviour," Organizational Behaviour and Human Decision Processes, vol. 50, no. 2, pp.179-211, 1991.

[9] M. Fishbein and I. Ajzen, Belief, attitude, intention and behavior: An introduction to theory and research. Reading, MA: Addison-Wesley, 1975.

[10] I. Ajzen and M. Fishbein, Understanding attitudes and predicting social behavior. Englewood Cliffs, NJ: Prentice Hall, 1980.

[11] I. Ajzen, "From intentions to actions: A theory of planned behaviour," in Action-control: From cognition to behaviour, J. Kuhl \& J. Beckmann Eds. New York: Springer, 1985, pp. 11-39.

[12] M. Tonglet, P.S. Phillips and A.D. Read, "Using the Theory of Planned Behaviour to investigate the determinants of recycling behaviour: A case study from Brixworth, UK" Resources. Conservation and Recycling, vol. 41, pp. 191-214, 2004. 
[13] D. Sirdeshmukh, J. Singh and B. Sabol, "Consumer trust, value, and loyalty in relational exchanges," Journal of Marketing, vol. 66, no 1, pp. 15-37, 2002.

[14] D. Gefen, E. Karahanna and D. Straub, "Trust and TAM in online shopping: An integrated model," MIS Quarterly, vol. 27, no. 1, 2003.

[15] D. McKnight, L. Cummings and N. Chervany, "Initial trust formation in new organizational relationships," The Academy of Management Review, vol. 23, no. 3, pp. 473-490, 1998.

[16] C. Hsiao and C. Yang, "Predicting the Travel Intention to Take High Speed Rail among College Students," Transport Research Part F, vol. 13, pp. 277-287, 2010.

[17] S. Jang and R. Feng, "Temporal destination revisit intention: The effects of novelty seeking and satisfaction," Tourism Management, vol. 28, no. 2, pp. 580-590, 2007.

[18] A. Bhattacherjee, "Acceptance of e-commerce services: The case of electronic brokerages," IEEE Transactions on Systems, Man and Cybernetics. Part A, vol. 30, no. 4, pp. 411-420, 2000.

[19] I. Ajzen and B. Driver, "Application of the theory of planned behavior to leisure choice," Journal of Leisure Research, vol. 24, no. 3, pp. 207-224, 1992.

[20] S. Taylor and P. Todd, "Understanding information technology usage: A test of competing models," Information Systems Research, vol. 6, pp. 144-176, 1995.

[21] A. Mehrabian and J. Russell, An Approach to Environmental Psychology. Cambridge, MA: MIT press, 1974.

[22] T. Lee and J. Crompton, "Measuring novelty seeking in tourism," Annals of Tourism Research, vol. 19, no. 4, pp. 732-751, 1992.

[23] J.C. Anderson and D.W. Gerbing, "Structural Equation Modeling in Practice: A Review and Recommended Two Step Approach," Psychological Bulletin, vol. 103, pp. 411-423, 1988.

[24] J.F. Hair, R.E. Anderson, R.L. Tatham and W.C. Black, Multivariate Data Analysis, (5th Edition). Upper Saddle River, NJ: Prentice Hall, 1998.

[25] J.L. Jackson, K. Dezee, K. Douglas and W. Shimeall, "Introduction to Structural Equation Modelling (Path Analysis)." SGIM Precourse, PA08, 2005.

[26] S. Haustein and M. Hunecke, "Reduced Use of Environmentally Friendly Modes of Transport Caused By Perceived Mobility Necessities - An Extension of the Theory of Planned Behaviour," Journal of Applied Social Psychology, vol. 37, pp. 1856-1883, 2007.

[27] K.I. Lee and R. Gould, "Predicting congregate meal program participation: applying the extended theory of planned behaviour," International journey of hospitality management, vol. 31, no. 3, pp. 828-836, 2011.

[28] C. Fornell and D.F. Larcker, "Evaluating structural equation models with unobservable variables and measurement error," Journal of Marketing Research, vol. 18, no. 1, pp. 39-50, 1981.

[29] H. Baumgartner and C. Homburg, "Applications of structural equation modeling in marketing and consumer research: A review," International Journal of Research in Marketing, vol. 13, no. 2, pp. 139-161, 1996.

[30] M. Boudreau, D. Gefen and D. Straub, "Validation in information systems research: A state-of-the-art assessment," MIS Quarterly, vol. 25, no. 1, pp. 1-16, 2001.

[31] B. Sheppard, J. Hartwick, and P. Warshaw, "The theory of reasoned action: A meta-analysis of past research with recommendations for modifications and future research," Journal of Consumer Research, vol. 15, no. 3, pp. 325343, 1988.

[32] L. Berry, "Relationship marketing of services - growing interest, emerging perspectives," Journal of the Academy of Marketing Science, vol. 23, no. 4, pp. 236-245, 1995. 